\title{
Using microsatellite markers to analyze genetic diversity in 14 sheep types in Iran
}

\author{
Mohammad Taghi Vajed Ebrahimi, Mohammadreza Mohammadabadi, and Ali Esmailizadeh \\ Department of Animal Science, Faculty of Agriculture, Shahid Bahonar University of Kerman, Kerman, Iran \\ Correspondence to: Mohammadreza Mohammadabadi (mmohammadabadi@yahoo.ca)
}

Received: 14 February 2017 - Revised: 4 May 2017 - Accepted: 13 June 2017 - Published: 11 July 2017

\begin{abstract}
Investigation of genetic relationship among populations has been traditionally based on the analysis of allele frequencies at different loci. The prime objective of this research was to measure the genetic polymorphism of five microsatellite markers (McMA2, BM6444, McMA26, HSC, and OarHH35) and study genetic diversity of 14 sheep types in Iran. Genomic DNA was extracted from blood samples of 565 individuals using an optimized salting-out DNA extraction procedure. The polymerase chain reaction (PCR) was successfully performed with the specific primers. Some locus-population combinations were not at Hardy-Weinberg equilibrium $(P<0.05)$. The microsatellite analysis revealed high allelic and gene diversity in all 14 breeds. Pakistani and Arabi breeds showed the highest mean number of alleles (11.8 and 11 respectively), while the highest value for polymorphic information content was observed for the Arabi breed (0.88). A UPGMA (unweighted pair group method with arithmetic mean) dendrogram based on the Nei's standard genetic distance among studied breeds showed a separate cluster for Arabi and Pakistani breeds and another cluster for other breeds. The Shannon index (H0) for McMA2, BM6444, McMA26, HSC, and OarHH35 was 2.31, 2.17, 2.27, 2.04 and 2.18, respectively, and polymorphic information content (PIC) values were $0.88,0.92,0.87,0.84$, and 0.86 for McMA2, BM6444, McMA26, HSC, and OarHH35, respectively. The high degree of variability demonstrated within the studied sheep types implies that these populations are rich reservoirs of genetic diversity that must be preserved.
\end{abstract}

\section{Introduction}

Small ruminants, especially native breed types, play an important role in the livelihoods of a considerable part of human population in the tropics from socioeconomic aspects. Therefore, an integrated attempt in terms of management and genetic improvement to enhance production is of crucial importance (Mohammadabadi and Sattayimokhtari, 2013). Economical and biological efficiency of sheep production enterprises generally improves by increasing productivity and reproductive performance of ewes (Mohammadabadi and Sattayimokhtari, 2013). There are more than 50 million sheep in Iran, of 27 breeds and ecotypes (Khodabakhshzadeh et al., 2016) that have not defined well as distinct breeds. However, they are considered as geographically defined populations. The need to maintain and improve local genetic resources has been recognized as a priority at the world level. Biodiversity studies depicting a deep picture of the genetic variability of the available sheep breeds provide favorable opportunities for both genetic conservation programs and enhancing production efficiency by means of controlled and well-designed crossbreeding systems exploiting breed diversities, heterosis and breed complementarity (Esmailizadeh et al., 2012).

Genetic diversity in indigenous breeds is a major concern considering the necessity of preserving what may be a precious and irreplaceable richness with regard to new productive demands (Khodabakhshzadeh et al., 2016). Conservation should be based on a deep knowledge of the genetic resources of the specific breed (Zamani et al., 2015). Therefore, it is important to try to characterize genetically indigenous breeds. Genes affecting polygenic traits and characterizing milk or meat productions are difficult to identify (Soufy et al., 2009; Shojaei et al., 2011). The maintenance of genetic diversity in livestock species requires the adequate implementation of conservation priorities and sustainable management programs, which should be based on comprehensive information regarding the structure of the populations, includ- 
ing sources of genetic variability among and within breeds. Genetic diversity is an essential component for population survival, evolution, genetic improvement and adaptation to changing environmental conditions (Kumar et al., 2006). Molecular methods based on molecular markers, such as random amplification of polymorphic DNA (RAPD), restriction fragment length polymorphism (RFLP) and microsatellites, are useful tools to study the genetic variations. Short tandem repeats known as microsatellites are widely used as molecular markers of choice for genetic studies. Advantages of microsatellites are a high degree of polymorphism due to existence of several alleles at each locus, their large number, distribution throughout the genome, a high level of polymorphism, neutrality with respect to selection, codominant inheritance and easy automation of analytical procedures (Canon et al., 2006; Mohammadifar et al., 2009; Mohammadabadi et al., 2010). Several studies have investigated the genetic diversity in sheep using microsatellites (Buchanan and Thue, 1998; Esmaeilkhanian and Banabazi, 2006; Bhatia and Arora, 2007; Nanekarani et al., 2010; Sun et al., 2010; Jakaria et al., 2012; Musthafa Muneeb et al., 2012; Hepsibha et al., 2013; Crispim et al., 2014), but a study of all Iranian sheep together has not been performed until now. Hence, the aim of the present study was to evaluate the genetic diversity within and between 14 sheep types in Iran (Kermani, Pakistani, Lori, Arabi, Dalagh, Baluchi, Iran-Black, Gharegol, Arman, Lori-Bakhtiari, Kermani-Pakistani, KermaniRomanov, Lori-Bakhtiari-Romanov and Lori-BakhtiariPakistani) using five microsatellite markers and to measure the distance among these breeds.

\section{Materials and methods}

\subsection{Animals and sampling}

In this study, 565 blood samples were collected from different individuals of 14 sheep types in Iran (Kermani (KER), $n=102$ (75 females and 27 males); Pakistani (PAK), $n=25$ (20 females and 5 males); Lori (LOR), $n=45$ (36 females and 9 males); Arabi (ARB), $n=47$ (34 females and 13 males); Dalagh (DAL), $n=44$ (32 females and 12 males); Baluchi (BAL), $n=41$ (30 females and 11 males); IranBlack (IRB), $n=44$ (40 females and 4 males); Gharegol (GHA), $n=43$ (33 females and 10 males); Arman (ARM), $n=46$ (31 females and 15 males); Lori-Bakhtiari (LRB), $n=25$ (19 females and 6 males); Kermani-Pakistani (KERPAK), $n=7$ (4 females and 3 males); Kermani-Romanov (KER-ROM), $n=48$ (28 females and 20 males); LoriBakhtiari-Romanov (LRB-ROM), $n=33$ (20 females and 13 males); and Lori-Bakhtiari-Pakistani (LRB-PAK), $n=$ 15 (8 females and 7 males)). Five-milliliter blood samples of both sexes were collected via the jugular vein in tubes containing EDTA for prevention of coagulation. Genomic DNA was extracted using a modified salting-out method (Abadi et al., 2009). DNA quality definition was determined using both spectrophotometry and agarose gel $(0.8 \%)$.

\subsection{Microsatellite analysis}

In this study, five microsatellite markers across the sheep genome were used. Gradient PCR was used to optimize the annealing temperature for each marker. The PCR products were tested in agarose gel $(0.8 \%)$ to estimate the best annealing temperature for each primer. The studied microsatellite markers, their primer sequences, detected annealing temperature and their allele size ranges are shown in Table 1. The selected microsatellites were amplified with PCR using genomic DNA extracted from individual animals (in total $25 \mathrm{~mL}$ ). This mixture included $2.5 \mathrm{~mL}$ of PCR buffer, $1 \mathrm{~mL}$ of $\mathrm{MgCl}_{2}, 0.5 \mathrm{~mL}$ of dNTP mix, $0.3 \mathrm{~mL}$ of Taq DNA polymerase, $16.7 \mathrm{~mL}$ of sterile water and $2 \mathrm{~mL}$ of template DNA. The reaction conditions were $94^{\circ} \mathrm{C}$ for $5 \mathrm{~min}$; $30 \mathrm{cy}-$ cles of $95^{\circ} \mathrm{C}$ for $30 \mathrm{~s}$; annealing temperature, differing for each primer (Table 1), for $45 \mathrm{~s}$ and $72^{\circ} \mathrm{C}$ for $30 \mathrm{~s}$; and final extension at $72{ }^{\circ} \mathrm{C}$ for $5 \mathrm{~min}$. A $50 \mathrm{bp}$ DNA ladder was used as a standard size for sizing PCR products. The PCR products were electrophoresed at $200 \mathrm{~V}$ for 60 to $90 \mathrm{~min}$ on the $8.0 \%$ polyacrylamide gel and visualized by staining with silver nitrate; the genotypes were scored by UVIdoc software after drying and scanning the gels.

\subsection{Statistical analysis}

Genotypes were assigned for each animal based on allele size data. Frequencies and number of alleles for each locus, observed and expected heterozygosity were estimated using FSTAT (version 2.9.3.2) (Goudet, 2002). The polymorphic information content (PIC) value was calculated according to Buchanan and Thue (1998). Nei's standard genetic distances (DS) among populations were computed by POPGENE (Yeh et al., 1999). This software was also used to construct the dendrogram of unweighted pair group with arithmetic mean (UPGMA).

\section{Results}

\subsection{Allelic diversity}

The PCR reactions were successfully performed with all primers. All the microsatellite loci were found to be highly polymorphic. In total, 65 alleles were detected; the HSC marker in PAK sheep breed and overall showed the highest number of alleles per locus (14 and 15 alleles respectively) while the OarHH35 marker in KER-PAK Sheep tape showed the lowest number of alleles (5 alleles) (Table 2) with a mean of $13 \pm 1.22$ alleles, whereas the effective number of alleles ranged from 3.26 (McMA2 marker) to 10.3 (McMA26 marker) with a mean of $6.59 \pm 0.96$ alleles per locus (Table 2). The number of actual and effective alleles of studied 
Table 1. Characteristics of selected microsatellite in present study.

\begin{tabular}{|c|c|c|c|c|c|c|}
\hline $\begin{array}{l}\text { Marker } \\
\text { (chromosome) }\end{array}$ & $\begin{array}{l}\text { Primers } \\
\left(5^{\prime}-3^{\prime}\right)\end{array}$ & $\begin{array}{l}\text { Accession } \\
\text { numbers* }\end{array}$ & $\begin{array}{l}\text { Type of } \\
\text { repeat }\end{array}$ & $\begin{array}{l}\text { Annealing } \\
\text { temperature } \\
\left({ }^{\circ} \mathrm{C}\right)\end{array}$ & $\begin{array}{l}\text { Allele size } \\
\text { range (bp) }\end{array}$ & Reference \\
\hline $\begin{array}{l}\text { McMA2 } \\
\text { (13) }\end{array}$ & $\begin{array}{l}\text { F: TCA CCC AAC AAT CAT GAA AC } \\
\text { R: TTA AAT CGA GTG TGA ATG GG }\end{array}$ & AF098773 & $\mathrm{AC}$ & 52 & $157-201$ & $\begin{array}{l}\text { Maddox et al. } \\
(2000)\end{array}$ \\
\hline $\begin{array}{l}\text { McMA26 } \\
(18)\end{array}$ & $\begin{array}{l}\text { F: TCT CTG CTT TCC AGC CTT ATT C } \\
\text { R: AGA GCT TTT AGG ACA GCC ACC }\end{array}$ & AF098961 & GT & 52.5 & $184-218$ & $\begin{array}{l}\text { Maddox et al. } \\
(2000)\end{array}$ \\
\hline $\begin{array}{l}\text { HSC } \\
(20)\end{array}$ & $\begin{array}{l}\text { F: CTG CCA ATG CAG AGA CAC AAG A } \\
\text { R: GTC TGT CTC CTG TCT TGT CAT C }\end{array}$ & M90759 & - & 60.2 & $267-301$ & NCBI \\
\hline $\begin{array}{l}\text { OarHH35 } \\
\text { (4) }\end{array}$ & $\begin{array}{l}\text { F: AAT TGC ATT CAG TAT CTT TAA } \\
\text { ACA TCT GGC } \\
\text { R: ATG AAA ATA TAA AGA GAA TGA } \\
\text { ACC ACA CGG }\end{array}$ & L12554 & GT & 59.7 & $87-170$ & $\begin{array}{l}\text { Henry } \\
\text { et al. (1993) }\end{array}$ \\
\hline $\begin{array}{l}\text { BM6444 } \\
\text { (2) }\end{array}$ & $\begin{array}{l}\text { F: CTC TGG GTA CAA CAC TGA GTC C } \\
\text { R: TAG AGA GTT TCC CTG TCC ATC C }\end{array}$ & G18444 & GT & 57.5 & $75-178$ & $\begin{array}{l}\text { Buchanan et al. } \\
\text { (1998) }\end{array}$ \\
\hline
\end{tabular}

* http://www.ncbi.nlm.nih.gov:80/entrez/viewer.cgi; F: forward; R: reverse

Table 2. The number of actual alleles $(\mathrm{Na})$ and effective alleles $(\mathrm{Ne})$ for different combinations of locus-population and for each population.

\begin{tabular}{|c|c|c|c|c|c|c|c|c|c|c|c|}
\hline \multirow{2}{*}{$\begin{array}{l}\text { Marker } \\
\text { Breed }\end{array}$} & \multicolumn{2}{|c|}{ McMA2 } & \multicolumn{2}{|c|}{ BM6444 } & \multicolumn{2}{|c|}{ McMA26 } & \multicolumn{2}{|c|}{ HSC } & \multicolumn{2}{|c|}{ OarHH35 } & \multirow[t]{2}{*}{ Mean $(\mathrm{Ne})$} \\
\hline & $\mathrm{Ne}$ & $\mathrm{Na}$ & $\mathrm{Ne}$ & $\mathrm{Na}$ & $\mathrm{Ne}$ & $\mathrm{Na}$ & $\mathrm{Ne}$ & $\mathrm{Na}$ & $\mathrm{Ne}$ & $\mathrm{Na}$ & \\
\hline ARB & 8.2 & 11 & 7.7 & 11 & 10.3 & 12 & 10.1 & 12 & 7 & 9 & 8.6 \\
\hline ARM & 7.88 & 10 & 7.1 & 9 & 7.9 & 11 & 6.3 & 7 & 7.1 & 9 & 7.2 \\
\hline BAL & 8.7 & 12 & 8.04 & 11 & 7.3 & 11 & 6.2 & 8 & 7.07 & 9 & 7.4 \\
\hline DAL & 8.56 & 12 & 8.01 & 10 & 7.7 & 11 & 5.5 & 6 & 5.9 & 8 & 7.1 \\
\hline GHA & 7.73 & 11 & 7.29 & 10 & 8.04 & 11 & 6.08 & 8 & 8.6 & 12 & 7.5 \\
\hline IRB & 8.56 & 12 & 5.28 & 8 & 8.01 & 10 & 4.36 & 8 & 7.75 & 11 & 6.8 \\
\hline KER & 10.22 & 12 & 7.25 & 8 & 8.38 & 11 & 6 & 7 & 7.52 & 10 & 7.8 \\
\hline KER-PAK & 3.26 & 6 & 3.76 & 6 & 4.08 & 7 & 4.9 & 6 & 4.66 & 5 & 4.13 \\
\hline KER-ROM & 8.15 & 12 & 6.41 & 9 & 5.48 & 9 & 6.4 & 7 & 6.5 & 10 & 6.59 \\
\hline LOR & 7.27 & 10 & 7.14 & 9 & 8.42 & 12 & 4.39 & 5 & 7.19 & 9 & 6.85 \\
\hline LRB & 6.31 & 12 & 6.21 & 13 & 5.23 & 10 & 4.61 & 7 & 5.38 & 9 & 5.5 \\
\hline LRB-ROM & 4.69 & 11 & 4.03 & 9 & 5.62 & 10 & 4.01 & 7 & 6.05 & 8 & 4.8 \\
\hline LRB-PAK & 3.46 & 9 & 3.94 & 8 & 4.68 & 9 & 4.5 & 6 & 4.68 & 6 & 4.2 \\
\hline PAK & 5.23 & 10 & 4.96 & 11 & 6.06 & 11 & 7.81 & 14 & 6.21 & 13 & 6.05 \\
\hline Overall & 8.48 & 12 & 7.24 & 13 & 8.08 & 12 & 6.5 & 15 & 7.4 & 13 & 7.54 \\
\hline
\end{tabular}

sheep types has been shown in Table 2. Among the sheep, the mean number of alleles ranged from 6 in KER-PAK to 11.8 in PAK sheep.

\subsection{Polymorphism information content (PIC) and Shannon's information index (I)}

PIC and the Shannon information index are another measure of genetic variability indicating the informativeness of the assessed loci. PIC values ranged from 0.84 (HSC marker) to 0.92 (BM6444 marker) with a mean PIC value of 0.87 (Table 3), indicating that all loci were highly polymorphic.
Table 3. Polymorphic information content (PIC), Shannon information index (I) and expected heterozygosity $\left(H_{\mathrm{e}}\right)$ in 14 sheep types.

\begin{tabular}{llll}
\hline Marker & PIC & I & $H_{\mathrm{e}}$ \\
\hline McMA2 & 0.88 & 2.31 & 0.87 \\
BM6444 & 0.92 & 2.17 & 0.86 \\
McMA26 & 0.87 & 2.27 & 0.87 \\
HSC & 0.84 & 2.04 & 0.82 \\
OarHH35 & 0.86 & 2.18 & 0.87 \\
\hline Mean & 0.87 & 2.2 & 0.85 \\
\hline
\end{tabular}


Table 4. Mean polymorphic information content (PIC), mean Shannon information index $(\mathrm{I})$, mean expected heterozygosity $\left(H_{\mathrm{e}}\right)$ and mean number of actual alleles (MNa) per type across five loci.

\begin{tabular}{lllll}
\hline Breed & PIC & I & $H_{\mathrm{e}}$ & $\mathrm{MNa}$ \\
\hline ARB & 0.88 & 2.27 & 0.88 & 11 \\
ARM & 0.87 & 2.09 & 0.86 & 9.2 \\
BAL & 0.86 & 2.15 & 0.86 & 10.2 \\
DAL & 0.84 & 2.07 & 0.85 & 9.4 \\
GHA & 0.87 & 2.17 & 0.86 & 10.4 \\
IRB & 0.84 & 2.05 & 0.84 & 9.8 \\
KER & 0.86 & 2.14 & 0.87 & 9.6 \\
KER-PAK & 0.73 & 1.58 & 0.75 & 6 \\
KER-ROM & 0.85 & 2.04 & 0.84 & 9.4 \\
LOR & 0.84 & 2.02 & 0.84 & 9 \\
LRB & 0.80 & 1.97 & 0.81 & 10.2 \\
LRB-ROM & 0.78 & 1.83 & 0.79 & 9 \\
LRB-PAK & 0.72 & 1.69 & 0.76 & 7.6 \\
PAK & 0.82 & 2.08 & 0.83 & 11.8 \\
Overall & 0.87 & 2.20 & 0.86 & 13 \\
\hline Mean & 0.82 & 2.01 & 0.83 & 9.47 \\
\hline
\end{tabular}

\subsection{Heterozygosity and interbreed inbreeding estimate}

The mean expected heterozygosity over all breeds in the present study was 0.85 (Table 3), so it does not likely encounter problems that result from inbreeding depression. Mean estimates of expected heterozygosity overall loci and types were 0.86 (Table 4$)$. ARB had the highest expected heterozygosity for all the loci $\left(H_{\mathrm{e}}=0.88\right)$ with an average number of actual allele of $\mathrm{Na}=11$, while KER-PAK had the lowest expected heterozygosity $\left(H_{\mathrm{e}}=0.75\right)$ with an average number of actual allele of $\mathrm{Na}=6$ (Table 4$)$.

\subsection{Hardy-Weinberg equilibrium (HWE)}

When the Hardy-Weinberg testing was performed for the loci, deviations from the Hardy-Weinberg equilibrium were found to be significant $(p<0.05)$ in some loci in several breeds (29 out of the 70 population-locus combinations $(41.4 \%)$ were at Hardy-Weinberg equilibrium).

\subsection{Genetic differentiation}

Population differentiation examined by fixation indices such as $F_{\mathrm{IS}}, F_{\mathrm{IT}}$ and $F_{\mathrm{ST}}$ for each of the five analyzed loci across 14 sheep breeds is given in Table 5. The genetic relationships between the sheep breeds were calculated using Nei's genetic distances $(D)$ (Nei et al., 1983). The matrix of Nei's standard genetic distances $(D)$ among breeds is presented in Table 6 and the corresponding phylogenetic tree is presented in Fig. 1. The genetic distances between breeds ranged from 0.04 for Kermani and Kermani-Pakistani to 0.25 for Kermani and Lori-Bakhtiari-Pakistani. The phylogenetic tree (Fig. 1) provides a method of visualizing the genetic relationship be-

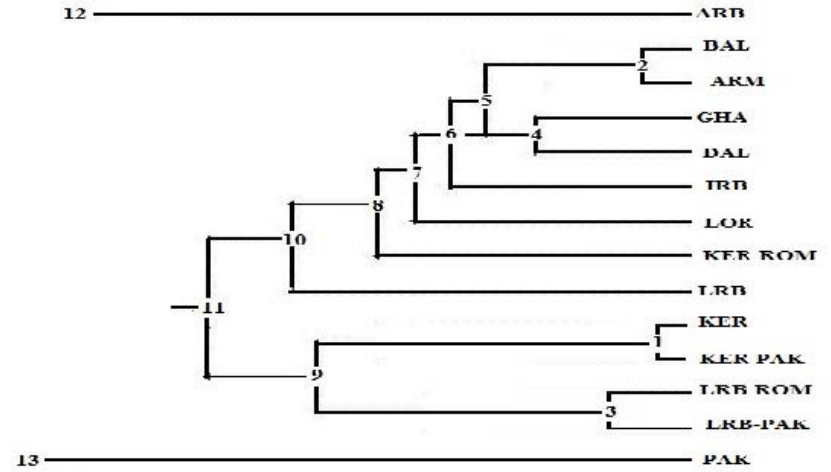

Figure 1. UPGMA phylogenetic tree based on Nei genetic distance. Location of these 14 studied breeds is shown in Fig. 2. Subspecies are indicated as Kermani (KER), Pakistani (PAK), Lori (LOR), Arabi (ARB), Dalagh (DAL), Baluchi (BAL), Iran-Black (IRB), Gharegol (GHA), Arman (ARM), Lori-Bakhtiari (LRB), KermaniPakistani (KER-PAK), Kermani-Romanov (KER-ROM), LoriBakhtiari-Romanov (LRB-ROM) and Lori-Bakhtiari-Pakistani (LRB-PAK).

Table 5. Estimators of F statistics at each locus across the 14 sheep types.

\begin{tabular}{llll}
\hline Marker & $F_{\mathrm{IS}}$ & $F_{\mathrm{IT}}$ & $F_{\mathrm{ST}}$ \\
\hline McMA2 & 0.0358 & 0.0624 & 0.0276 \\
BM6444 & 0.0149 & 0.0394 & 0.0248 \\
McMA26 & 0.0162 & 0.0390 & 0.0232 \\
HSC & 0.1075 & 0.1317 & 0.0271 \\
OarHH35 & 0.0356 & 0.0530 & 0.0181 \\
\hline Mean & 0.042 & 0.0651 & 0.0241 \\
\hline
\end{tabular}

tween populations, with the values in the nodes of the tree indicating the proportion of 1000 replicates of the 5 microsatellites.

\section{Discussions}

Genetic variation is a basic requirement for animal breeding, whereas a high genetic variation is needed for genetic improvement of domestic animals (Askari et al., 2011). The number of alleles at different marker loci serves as a measure of the genetic variability having direct impact on differentiation of breeds within a species. Since $80 \%$ of the markers exhibited four or more alleles, the microsatellite loci screened in this study were appropriate in expressing the molecular characteristics and/or genetic variation in the population. The effective number of alleles at each locus provides information on predominant alleles. Since allelic diversity in the studied sheep breed populations was high, it can be concluded that, in these animals, genetic diversity is sufficiently high and they have a good gene pool for breeding programs. Because of the limitations in studied population number and 
Table 6. Genetic distance matrices based on $D_{\mathrm{A}}$ (upper diagonal matrix) and $D_{\mathrm{AL}}$ (lower diagonal matrix) using 1000 bootstrap replications.

\begin{tabular}{|c|c|c|c|c|c|c|c|c|c|c|c|c|c|c|}
\hline & ARB & ARM & BAL & DAL & GHA & IRB & KER & KERPAK & KERROM & LOR & LRB & LRBROM & LRBPAK & PAK \\
\hline ARB & - & 0.87 & 0.87 & 0.85 & 0.88 & 0.85 & 0.82 & 0.8 & 0.85 & 0.86 & 0.84 & 0.83 & 0.8 & 0.81 \\
\hline ARM & 0.129 & - & 0.91 & 0.91 & 0.93 & 0.91 & 0.92 & 0.8 & 0.89 & 0.8 & 0.89 & 0.87 & 0.86 & 0.88 \\
\hline BAL & 0.128 & 0.05 & - & 0.92 & 0.85 & 0.93 & 0.9 & 0.84 & 0.89 & 0.84 & 0.89 & 0.86 & 0.87 & 0.86 \\
\hline DAL & 0.15 & 0.08 & 0.07 & - & 0.91 & 0.91 & 0.81 & 0.82 & 0.89 & 0.85 & 0.89 & 0.83 & 0.84 & 0.88 \\
\hline GHA & 0.125 & 0.07 & 0.06 & 0.09 & - & 0.84 & 086 & 0.84 & 0.87 & 0.85 & 0.86 & 0.88 & 0.88 & 0.87 \\
\hline IRB & 0.15 & 0.09 & 0.07 & 0.08 & 0.08 & - & 0.87 & 0.83 & 0.9 & 0.87 & 0.91 & 0.89 & 0.88 & 0.87 \\
\hline KER & 0.18 & 0.08 & 0.09 & 0.1 & 0.14 & 0.13 & - & 0.93 & 0.89 & 0.87 & 0.84 & 0.79 & 0.77 & 0.84 \\
\hline KERPAK & 0.21 & 0.21 & 0.17 & 0.18 & 0.16 & 0.17 & 0.04 & - & 0.82 & 0.81 & 0.85 & 0.84 & 0.91 & 0.83 \\
\hline KERROM & 0.15 & 0.21 & 0.09 & 0.11 & 0.09 & 0.09 & 0.1 & 0.19 & - & 0.82 & 0.87 & 0.86 & 0.087 & 0.86 \\
\hline LOR & 0.14 & 0.11 & 0.06 & 0.08 & 0.07 & 0.06 & 0.13 & 0.2 & 0.09 & - & 0.9 & 0.88 & 0.87 & 0.87 \\
\hline LRB & 0.17 & 0.11 & 0.09 & 0.1 & 0.09 & 0.08 & 0.16 & 0.16 & 0.13 & 0.1 & - & 0.94 & 0.9 & 0.88 \\
\hline LRBROM & 0.18 & 0.13 & 0.14 & 0.17 & 0.11 & 0.1 & 0.23 & 0.16 & 0.14 & 0.12 & 0.08 & - & 0.92 & 0.87 \\
\hline LRBPAK & 0.21 & 0.14 & 0.13 & 0.17 & 0.11 & 0.12 & 0.25 & 0.08 & 0.13 & 0.13 & 0.09 & 0.06 & - & 0.91 \\
\hline PAK & 0.2 & 0.12 & 0.13 & 0.12 & 0.12 & 0.13 & 0.17 & 0.18 & 0.14 & 0.13 & 0.08 & 0.13 & 0.12 & - \\
\hline
\end{tabular}

microsatellite loci, further research with more population and loci numbers needs to be done to be able correctly evaluate the genetic relationship among the populations. However, a higher number of alleles for each locus showed that all the markers used were appropriate to analyze diversity in studied breeds. The level of variation depicted by number of alleles at each locus was similar to earlier reports on sheep breeds (Arora and Bhatia, 2006; Jakaria et al., 2012; Hepsibha et al., 2013; Crispim et al., 2014).

Among the types, the mean of PIC ranged from 0.72 in LRB-PAK to 0.88 in ARB, and Shannon information index ranged from 1.58 in KER-PAK to 2.27 in ARB. . However, PIC in the range of 0.69 to 0.92 was reported for this locus in some Iranian sheep breeds in a previous study (Esmaeilkhanian and Banabazi, 2006; Banabazi et al., 2007; Nanekarani et al., 2010). Our estimate of Shannon information index was in agreement with that reported by Nanekarani et al. (2010) on three types of Iranian sheep populations and Musthafa Muneeb et al. (2012) on Najdi sheep populations. This index estimate was higher than that of Mehraban sheep (Zamani et al., 2011) and Indian Bellary sheep (Kumar et al., 2006).

A high value of average expected heterozygosity within a breed could be attributed to the large number of alleles detected in the tested loci (Kalinwski, 2002). The high heterozygosity is attributed to the wider distribution of population and to presumably the larger flock size. It also proves that no controlled breeding is followed as males and females are allowed to graze as a large flock. Heterozygosity values were in concordance with those of Najdi sheep populations (Musthafa Muneeb et al., 2012), Indian sheep breeds (Bhatia and Arora, 2007) and five Iranian indigenous sheep populations (Esmaeilkhanian and Banabazi, 2006). The expected heterozygosity in this study was higher than that of some of loci (OarHH35) used in Hu sheep in China (Sun et al., 2010). Thus, differences of heterozygosity values obtained could be due to type of markers used, the sequence of simple sequence repeat (SSR) markers, and sampling and sample size.
In total, $58.6 \%$ of the loci in some breeds deviated from HWE $(p<0.05)$. This can be attributed to the excess of heterozygote individuals than homozygote individuals, migration, high mutation rate in microsatellite, artificial selection in all breeds and population subdivision owing to genetic drift (Aminafshar et al., 2008). Deviation from HWE at microsatellite loci has also been reported in various studies (Esmaeilkhanian and Banabazi, 2006; Banabazi et al., 2007; Nanekarani et al., 2010; Jakaria et al., 2012; Hepsibha et al., 2013; Crispim et al., 2014). It is known that a population is considered to be in HWE only when it is able to maintain its relative allelic frequencies. This deviation from HWE can be probably due to level of crossbreeding in some populations. However, crossbreeding of local and exotic improved breeds can show a faster impact on performance than long selection schemes for the improvement of local breeds; therefore, it is more beneficial in the short term. However, as another consequence, it is one of the major threats to the existence of local genetic diversity, inducing displacement or genetic erosion. Indiscriminate crossbreeding or extensive use of exotic germplasms can lead to genetic erosion by dilution or eradication of the local genetic pool; hence, it is better to use controlled crossbreeding.

The within-breed inbreeding estimate $\left(F_{\mathrm{IS}}\right)$ in the investigated population was found to be low and similar to a value of $0.0024 \pm 0.07$ reported by Pariset et al. (2003). This indicates that the population has not suffered any inbreeding but rather has a heterozygosity excess. Further, a high level of expected heterozygosity in this study correlates with the low $F_{\text {IS }}$ value, suggesting low selection pressure, no inbreeding and relatively more alleles.

There are three separate clusters on the dendrogram. One includes 12 breeds and another consists of Arabi and then Pakistani in a separate branch. Since $D_{\mathrm{A}}$ has been found to be more useful for obtaining of correct topology (Takezaki and Nei, 1996), we presented only the results of $D_{\mathrm{A}}$. The lowest $D_{\mathrm{A}}$ was between Kermani and Kermani-Pakistani and 


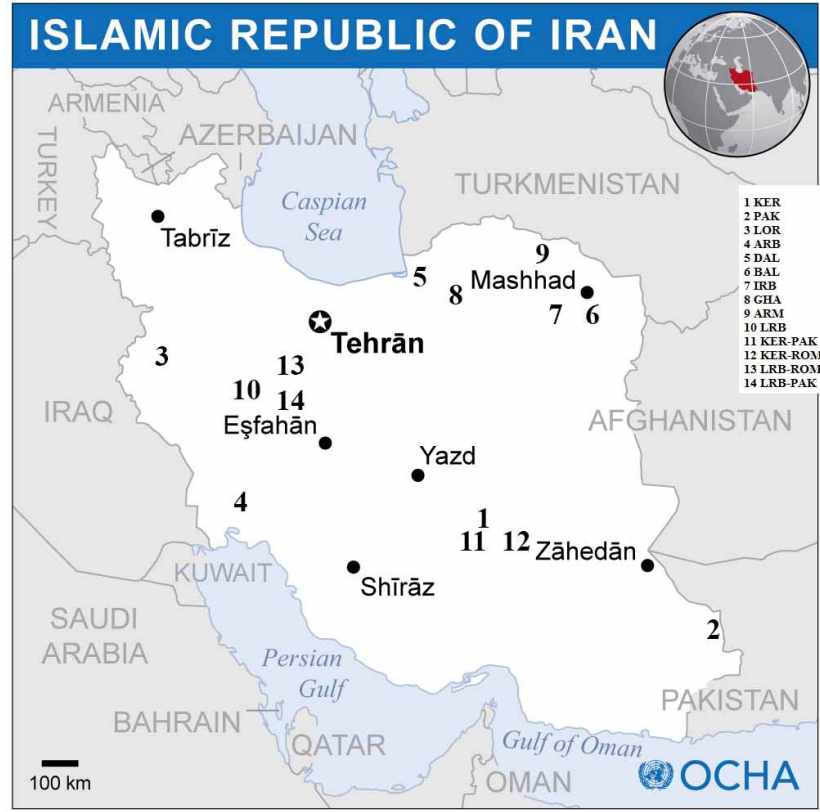

Map Sources: ESRI, UNCS.

The boundaries and names shown and the designations used on this map do not imply official endorsement or acceptance by the United Nations. Map created in Sep 2013.

Figure 2. Location of the 14 study sites in Iran. The putative subspecies are indicated as Kermani (KER), Pakistani (PAK), Lori (LOR), Arabi (ARB), Dalagh (DAL), Baluchi (BAL), Iran-Black (IRB), Gharegol (GHA), Arman (ARM), Lori-Bakhtiari (LRB), Kermani-Pakistani (KER-PAK), KermaniRomanov (KER-ROM), Lori-Bakhtiari-Romanov (LRB-ROM) and Lori-Bakhtiari-Pakistani (LRB-PAK). Source of original map: OCHA/ReliefWeb (http://img.static.reliefweb.int/sites/ reliefweb.int/files/resources/irn_ocha_1000px.png).

between Baluchi and Arman (Table 6). These distances are rational due to co-descendance of two breeds of sheep and neighboring geographic distributions. Their phenotypic similarities also agree with these distances. A possible crossmigration between Gharegol and Dalagh may occur due to the short geographic distance between the areas in which these two breeds are distributed resulted in small genetic distance between two breeds. The obtained tree revealed that the most closely related breeds were the two synthetic lines (Lori-Bakhtiari-Romanov and Lori-BakhtiariPakistani). Although one local breed (Lori-Bakhtiari) participated in the creation of two analyzed breeds, clear differences can be noticed. Also, the UPGMA tree showed that the Arabi forms the most distinct breed. The rugged topography and the Zagros Mountains (see Fig. 2) limit the movement of sheep and impose reproductive isolation between Arabi and other population distribution areas. Therefore, Arabi is in a separate branch.

\section{Conclusions}

The breeds included in this study are of great importance to the sheep holders in Iran. This study presents an investigation of variability at the DNA level within and between some Iranian sheep breeds. The results indicated that all studied breeds exhibited considerable genetic variation, based on their high mean number of alleles and gene diversity. According to the selective standard of microsatellite loci, microsatellite loci ought to have at least four alleles per locus to be considered useful for the evaluation of genetic diversity. Based on this criterion, the five microsatellite loci used in the present study can be considered useful for the evaluation of genetic diversity within and among populations and for the selection of breeding animals from divergent groups maximizing genetic variation and consequently fitness. A future direction to our study can be studying all of the Iranian indigenous sheep breeds to better evaluate the level of inbreeding and establish appropriate conservation strategies with the aim to avoid losses of genetic diversity.

Data availability. The original data of the paper are available upon request from the corresponding author.

Author contributions. $\mathrm{MM}$ and AEK designed this project, MTVE collected blood from animals and performed experiments in the laboratory, and MM and MTVE wrote the paper.

Competing interests. The authors declare that they have no conflict of interest.

Acknowledgements. We would like to thank the sheep farmers who provided sheep blood samples for this study.

Edited by: Steffen Maak

Reviewed by: Sonia Zakizadeh and Masood Asadi Fozi

\section{References}

Abadi, M. R. M., Askari, N., Baghizadeh, A., and Esmailizadeh, A.: A directed search around caprine candidate loci provided evidence for microsatellites linkage to growth and cashmere yield in Rayini goats, Small Ruminant Res., 81, 146-151, 2009.

Aminafshar, M., Amirinia, C., and Torshizi, R. V.: Genetic diversity in buffalo population of guilan using microsatellite marker, J. Anim. Vet. Adv., 7, 1499-1502, 2008.

Arora, R. and Bhatia, S.: Genetic diversity of Magra sheep from India using microsatellite analysis, Asian Austral. J. Anim., 19, 938-942, 2006.

Askari, N., Abadi, M. M., and Baghizadeh, A.: ISSR markers for assessing DNA polymorphism and genetic characterization of cat- 
tle, goat and sheep populations, Iran. J. Biotechnol., 9, 222-229, 2011.

Banabazi, M. H., Esmaeilkhanian, S., Miraei Ashtiani, S. R., and Moradi, S. M.: Genetic variation within and between five Iranian sheep populations using microsatellite markers, J. Sci. Technol. Agric. Nat. Resour., 10, 481-488, 2007 (Abstract in English).

Bhatia, S. and Arora, R.: Genetic diversity in Kheri-A pastoralists developed Indian sheep using microsatellite markers, Indian J. Biotechnol., 7, 108-112, 2007.

Buchanan, F. C. and Thue, T. D.: Interbreed polymorphic information content of microsatellites in cattle and sheep, Can. J. Anim. Sci., 78, 425-428, 1998.

Canon, J., Garćra, D., Garćia-Atance, M. A., Obexer-Ruff, G., Lenstra, J. A., Ajmone-Marsan, P., and Dunner, S.: The Econogene Consortium, Geographical partitioning of goat diversity in Europe and the Middle East, Anim. Genet., 37, 327-334, 2006.

Crispim, B. D. A., Seno, L. D. O., Egito, A. A. D. E., Junior, F. M. D. V., and Grisolia, A. B.: Application of microsatellite markers for breeding and genetic conservation of herds of Pantaneiro sheep, Electron. J. Biotechn., 17, 317-321, 2014.

Esmaeilkhanian, S. and Banabazi, M. H.: Genetic variation within and between five Iranian sheep populations using microsatellites markers, Pak. J. Biol. Sci., 13, 2488-2492, 2006.

Esmailizadeh, A. K., Nemati, M., and Mokhtari, M. S.: Fattening performance of purebred and crossbred lambs from fat-tailed Kurdi ewes mated to four Iranian native ram breeds, Trop. Anim. Health Prod., 44, 217-223, 2012.

Goudet, J.: FSTAT (version 2.9.3.2): a program to Estimate and Test gene Diversities and Fixation Indices, available at: http://www. softpedia.com/get/Science-CAD/FSTAT.shtml, 2002.

Henry, H. M., Penty, J. M., Pierson, C. A., and Crawford, A. M.: Ovine microsatellites at the OarHH35, OarHH41, OarHH44, OarHH47and OarHH64 loci, Anim. Genet., 24, 222-222, https://doi.org/10.1111/j.1365-2052.1993.tb00300.x, 1993.

Hepsibha, P., Karthickeyan, S. M. K., and Guru, V.: Microsatellite marker based assessment of genetic structure of Coimbatore breed of sheep Ovis Aries in Tamil Nadu, Indian J. Biotechnol., 13, 203-206, 2013.

Jakaria, Z., Sulandari, M. S., Subandriyo, A., and Muladno, S.: The use of microsatellite markers to study genetic diversity in Indonesian sheep, J. Indonesian Trop. Anim. Agric., 37, 1-9, 2012.

Kalinwski, S. T.: How many alleles per locus should be used to estimate genetic distances, Heredity, 88, 62-65, 2002.

Khodabakhshzadeh, R., Mohammadabadi, M. R., Esmailizadeh, A., Moradi Shahrebabak, H., Bordbar, F., and Ansari Namin, S.: Identification of point mutations in exon 2 of GDF9 gene in Kermani sheep, Pol. J. Vet. Sci., 19, 281-289, 2016.

Kumar, D., Sharma, R., Pandey, A. K., Gour, D. S., Malik, G., Ahlawat, S. P. S., and Jain, A.: Genetic diversity and bottleneck analysis of Indian Bellary sheep by microsatellite markers, Russ. J. Genet., 9, 996-1005, 2006.

Maddox, J. F., Riffkin, C. D., and Beh, K. J.: Dinucleotide repeat polymorphism at ovin MCMA1, MCMA2, MCMA5, MCMA8, MCMA9, MCMA11, MCMA14, MCMA20, MCMA24, MCMA26 loci, Anim. Genet., 31, 148-149, 2000.
Mohammadabadi, M. R. and Sattayimokhtari, R.: Estimation of (co) variance components of ewe productivity traits in Kermani sheep, Slovak. J. Anim. Sci., 46, 45-51, 2013.

Mohammadifar, A., Amirnia, S., Omrani, H., Mirzaei, H. R., and Mohammadabadi, M. R.: Analysis of genetic variation in quail population from Meybod Research Station using microsatellite markers, Pajouhesh and Sazandegi, 22, 72-79, 2009 (Abstract in English).

Mohammadabadi, M. R., Nikbakhti, M., Mirzaee, H. R., Shandi, M. A., Saghi, D. A., Romanov, M. N., and Moiseyeva, I. G.: Genetic variability in three native Iranian chicken populations of the Khorasan province based on microsatellite markers, Russ. J. Genet., 46, 572-576, 2010.

Musthafa Muneeb, M., Aljummah, R. S., and Alshaik, M. A.: Genetic diversity of Najdi sheep based on microsatellite analysis, Afr. J. Biotechnol., 1183, 14868-14876, 2012.

Nanekarani, S., Amirinia, C., Amirmozafari, N., Vaez Torshizi, R., and Gharahdaghi, A. A.: Genetic variation among pelt sheep population using microsatellite markers, Afr. J. Biotechnol., 9, 7437-7445, 2010.

Nei, M., Tajima, F., and Tateno, Y.: Accuracy of estimated phylogenetic trees from molecular data, J. Mol. Evol., 19, 153-170, 1983.

Pariset, L. M., Savarese, C., Cappuccio, I., and Valentini, A.: Use of microsatellites for genetic variation and inbreeding analysis in Sarda sheep flocks of central Italy, J. Anim. Breed. Genet., 120, 425-432, 2003.

Shojaei, M., Mohammadabadi, M. R., Asadi Foz, M., Dayani, O., Khezri, A., and Akhondi, M.: Association of growth trait and Leptin gene polymorphism in Kermani sheep, J. Cell Mol. Res., 2, 67-73, 2011.

Soufy, B., Mohammadabadi, M. R., Shojaeyan, K., Baghizadeh, A., Ferasaty, S., Askari, N., and Dayani, O.: Evaluation of Myostatin gene polymorphism in Sanjabi sheep by PCR-RFLP method, Anim. Sci. Res., 19, 81-89, 2009 (Abstract in English).

Sun, W., Chang, H., Hussein Musa, H., and Chu, M.: Study on relationship between microsatellite polymorphism and producing ability on litter size trait of $\mathrm{Hu}$ sheep in China, Afr. J. Biotechnol., 9, 8704-8711, 2010.

Takezaki, N. and Nei, M.: Genetic distances and reconstruction of phylogenetic trees from microsatellite DNA, Genetics, 144, 389399, 1996.

Yeh, F. C., Yang, R., and Boyle, T.: PopGene. Version 1.31. Microsoft Window-based Freeware for Population Genetic Analysis, University of Alberta, Edmonton, AB, Canada, 1999.

Zamani, P., Akhondi, M., Mohammadabadi, M. R., Saki, A. A., Ershadi, A., Banabazi, M. H., and Abdolmohammadi, A. R.: Genetic variation of Mehraban sheep using two intersimple sequence repeat (ISSR) markers, Afr. J. Biotechnol., 10, 18121817, 2011.

Zamani, P., Akhondi, M., and Mohammadabadi, M. R.: Associations of inter-simple sequence repeat loci with predicted breeding values of body weight in sheep, Small Ruminant Res., 132, 123-127, 2015. 